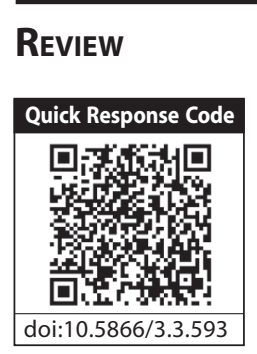

\title{
Mineral Trioxide Aggregate
}

Ravichandra P V', Jayaprada Reddy $\mathrm{S}^{2}$, Harikumar V' ${ }^{3}$ Kavita $\mathrm{A}^{4}$

Department of Conservative Dentistry Kamineni Institute of Dental Sciences, Narketpally, Nalgonda Dist. A.P.

Professor \& HOD ${ }^{1}$

Professors ${ }^{283}$

Senior Lecturer ${ }^{4}$

\begin{abstract}
:
Mineral trioxide aggregate, or MTA, is a new material developed for endodontics that appears to be a significant improvement over other materials for procedures in bone. It is the first restorative material that consistently allows for the overgrowth of cementum, and it may facilitate the regeneration of the periodontal ligament.In this article, we review the current dental literature on MTA, discussing its composition, physical,chemical and biological properties and clinical characteristics.
\end{abstract}

\section{Article Info}

Received: April 14, 2011

Review Completed: May, 16, 2011

Accepted: June, 19, 2011

Available Online: October, 2011

(C) NAD, 2011 - All rights reserved

Key words: Mineral Trioxide Aggregate, Composition, Mechanism of action, Physical and Chemical properties, clinical applications.

\section{INTRODUCTION}

Oral health is indeed a reflection of a wholesome lifestyle. Man's curiosity for new things and fascination for learning has led to revolution in every field, and dentistry is not been left behind. As therapeutic techniques become more sophisticated the management of problems encountered or created during treatment has also become increasingly complicated.

Every effort was put in to match the best endeavor, result was a totally versatile material MTA - compositionally formulated to have physical properties, settings requirements and characteristics necessary for an ideal repair and medicament material. ${ }^{4}$

Mineral trioxide aggregate, or MTA, is a new biocompatible material introduced by Mohmoud Email for correspondence: sjayaprada@yahoo.com
Taorabinejad with numerous exciting clinical applications in Endodontics. It has been used on an experimental basis by endodontists for several years with anecdotally reported success, some of it quite impressive; MTA's approval in 1998 by the U.S. Food and Drug Administration should lead to more widespread use. The material appears to be an improvement over other materials for endodontic procedures that involve root repair and bone healing.

\section{COMPOSITION:}

\section{MTA consists of fine hydrophilic particles}

- Tricalcium silicate

- Tricalcium aluminate

- Tricalcium oxide

- Silicate oxide

It also contains small amounts of mineral oxides, which modify its chemical and physical properties.Electron probe micro analysis of the MTA 
powder showed that calcium and phosphorus are the main ions present.

MTA is cement composed of tricalcium silicate, tricalcium aluminate, tricalcium oxide, silicate oxide and bismuth oxide. It also contains $5 \%$ calcium sulphate dehydrate and tetracalcium alumino ferrite.Off white colored formula lacks tetra calcium alumino ferrite and lack of this iron containing compound accounts for off white appearance.

Both the formula contains;

70\% Portland cements, 20\% bismuth oxide and $5 \%$ gypsum by weight.

\section{MANIPULATION:}

MTA is supplied as a powder. Each pack of Pro root MTA powder comes with a pre-measured unit dose of water for convenience in mixing.

\section{MIXING TIME:}

MTA is prepared by mixing 3 parts of powder with one part aqueous solution by weight to obtain a putty consistency which is achieved after 30 seconds of mixing.

MECHANISM OF ACTION: From the time that MTA is placed in direct contact with human tissues, it appears that the material does the following ${ }^{3}$

(1) Forms $\mathrm{CH}$ that releases calcium ions for cell attachment and proliferation

(2) Creates an antibacterial environment by its alkaline $\mathrm{pH}$

(3) Modulâtes cytokine production

(4) Encourages differentiation and migration of hard tissue-producing cells and

(5) Forms HA (or carbonated apatite) on the MTA surface and provides a biologic seal.

PHYSICAL, CHEMICAL, BIOLOGICAL AND HISTOLOGICAL PROPERTIES:

1. pH: 10.2 initially and it rose to 12.5 after 3 hours, and thereafter, it remained constant ${ }^{1,4,5}$

2. Radiopacity: radiopacity for MTA was $7-17 \mathrm{~mm}$ of equivalent thickness of aluminium, because it is more radiopaque than conventional gutta percha and dentin, it should be easily distinguishable on radiographs when used as a root filing material. ${ }^{1,4,5}$

3. Setting time: Advantages of its longer setting time are that, the quicker a material sets the more it shrinks. This explains why MTA in previous experiments had significantly less dye and bacterial leakage than other materials tested as root filling materials. ${ }^{1,4,5}$

4. Compressive strength: In 24 hours MTA had the lowest compressive strength (40 Mpa) among the materials (Amalgam, Super EBA \& IRM) tested, but it increased after 21 days to $67 \mathrm{MPa}$. The increase in compressive strength of MTA required the presence of moisture. ${ }^{1,4,5}$

5. Solubility: MTA shows no signs of solubility in water and this is a major factor in assessing the suitability of potential substances to be used as restorative materials in dentistry. Lack of solubility has been stated as an ideal characteristic for root end filing material. . $^{1,45}$

6. Biocompatibility: Application of MTA as a root end filling material promoters regeneration of dental and osseous tissues, and may induce cementoblasts to produce matrix for cementum formation over MTA. ${ }^{1,4,5}$

7. Sealing ability MTA has enhanced sealing ability which could be due to the setting expansion when it is used in moist oral environment. ${ }^{16,20}$

8. MTA has an antibacterial effect on some of the facultative bacteria and no effect on any of the strict anaerobic bacteria. The antibacterial effect of MTA against these organisms could be because of its alkaline $\mathrm{pH}$ or release of diffusible substances into the growth medium. ${ }^{11,18}$

9. MTA is an effective pulp capping material able to stimulate hard tissue bridge formation during the early wound healing process. The stereotypic pulp defence mechanism by which primitive matrix (fibro dentine) trigger expression of the odontoblastic potential of pulpal cells seems to be related to the dentinogenic activity of MTA. Pulp capping with MTA induces cytological and functional changes in pulpal cells resulting in formation of fibrodentine and reparative dentine at the surface of mechanically exposed dental pulps. ${ }^{7,10,15}$ 
10. In-vitro study of human osteoblasts revealed that MTA stimulated the release of cytokines and the production of interleukine. ${ }^{20}$

CLINICAL APPLICATIONS: $2,6,12,14,17,19$ IN PRIMARY TEETH:

- Pulp capping

- Pulpotomy

- Root canal filling

- Furcation perforation repair

- Resorption repair

IN PERMANENT TEETH:

- Pulp capping

- Partial pulpotomy

- Pulpotomy

- Root canal filling

- Perforation repair - apical, lateral, furcation

- Resorption repair - external \& internal

- Root end filling

- Apical barrier for tooth with necrotic pulps \& open apex

- $\quad$ Sealer \& others.....

- MTA has been successfully used for the treatment of strip and supracrestal perforations, horizontal root fractures, sealing communications between the root canal space and external root surfaces, filling root canals of teeth with mature and open apexes, as well as management of dens invaginatus.

\section{ADVANTAGES: ${ }^{3}$}

- High biocompatibility

- Hydrophilic

Radio-opaque

- Highly alkaline pH (Bacteriostatic)

- $\quad$ Excellent sealing ability (Low marginal leakage)

- Low solubility

\section{DISADVANTAGES: ${ }^{3}$}

- Discolouration potential (GMTA)

- Presence of toxic elements in the material composition (arsenic)

- Difficult handling characteristics
MTA as a root canal filling material include difficulty in obturation of curved root canals, discolouration potential \& long ST

- $\quad$ Long setting time

- High cost

- $\quad$ An absence of a known solvent for set MTA.

- Difficulty in removal after curing

\section{CONCLUSION:}

MTA is a new biocompatible material with numerous exciting clinical applications. It has been used on an experimental basis by dentists for several years with anecdotally reported success, some of it quite impressive. An ideal root repair material which has qualities like resistance to marginal leakage, allows normal healing response, ease of clinical manipulation non- resorbable. And finally the most important quality, especially of interest in our field it is non toxic. Because of all these superior qualities and a high ph similar to calcium hydroxide it is not surprising that induction of hard tissue formation often occurs after the use of this substance. So no longer are immature permanent teeth with carious lesion or traumatic pulp exposure destined for endodontic therapy.

\section{REFERENCES}

1. Parirokh $\mathrm{M}$ and Torabinejad M. Mineral trioxide aggregate: a comprehensive literature review- part I : chemical, Physical, and Antibacterial Properties. J Endod 2010;36:16-27.

2. Parirokh $\mathrm{M}$ and Torabinejad M. Mineral trioxide aggregate: a comprehensive literature review- part II : leakage and Biocompatibility Investigations J Endod 2010;36:190-202.

3. Parirokh M and Torabinejad M. Mineral trioxide aggregate: a comprehensive literature review- part III : clinical Applications, Drawbacks, and Mechanism of Action J Endod 2010;36:400-413.

4. Mahmoud Torabinejad and T.T, Pit Ford: Physical and chemical properties of a new root end filing materials. The American Association of Endodontics Vol, 21, No. 7 July 1995.

5. Santos AD, Moraes JC, Arau' jo EB, Yukimitu K, Vale'rio Filho WV. Physico-chemical properties of MTA and a novel experimental cement. Int Endod J 2005;38:443-447.

6. G. De-Deus, V. Petruccelli, E. Gurgel-Filho, T. Coutinho-Filho MTA versus Portland cement as repair material for furcal perforations: a laboratory study using a polymicrobial leakage model. Int Endod J 2006;39:293-298. 
7. Tziafas D, Pantelidou O, Alvanou A, Belibasakis G, Papadimitriou $S$. The dentinogenic effect of mineral trioxide aggregate (MTA) in short-term capping experiments. Int Endod J 2002;35:245-254.

8. Bargholz C. Perforation repair with mineral trioxide aggregate: a modified matrix concept. Int Endod J 2005;38:59-69.

9. Islam I, Chng HK, Yap AU. X-ray diffraction analysis of mineral trioxide aggregate and Portland cement. Int Endod J 2006;39:220-225.

10. Effect of Mineral trioxide aggregate on proliferation of cultured human dental pulp cells. Int Endod J,2006;39:415422.

11. Camilleri J,Pitt Ford TR.Mineral trioxide aggregate: a review of the constituents and biological properties of the material. Int Endod J 2006;39:747-54.

12. Felippe WT, Felippe MC, Rocha MJ. The effect of mineral trioxide aggregate on the apexification and periapical healing of teeth with incomplete root formation. Int Endod J 2006;39:2-9.

13. Song JS, Mante FK, Romanow WJ, Kim S. Chemical analysis of powder and set forms of Portland cement, gray ProRoot

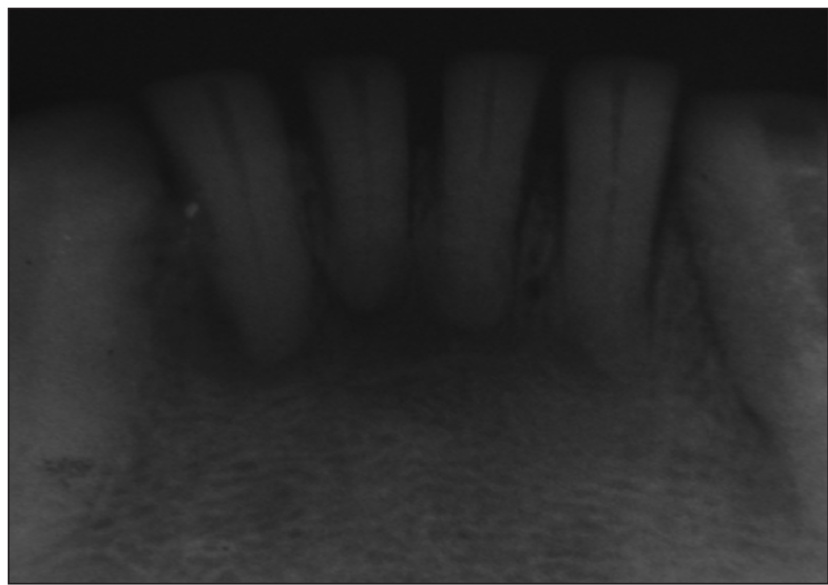

Figure 1: Pre-Op cervical Perforation

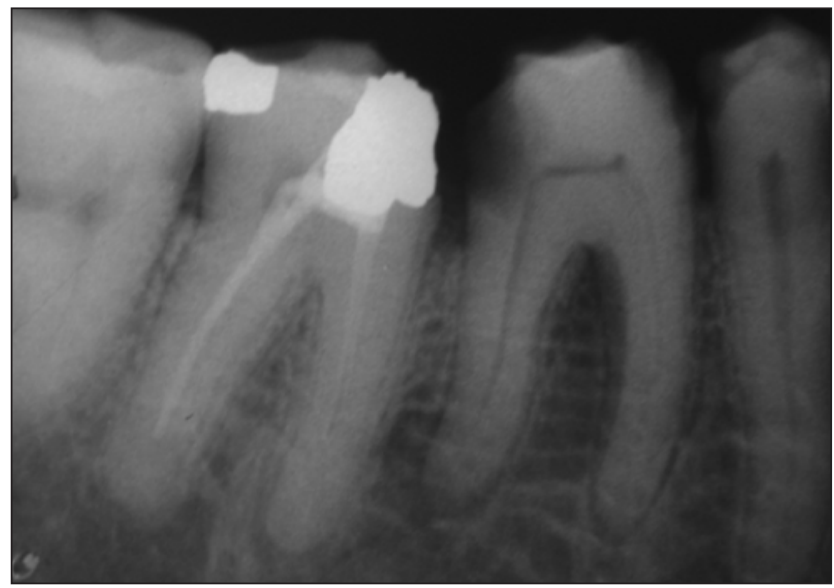

Figure 3: Pre-Op Furcation Perforation
MTA, white ProRoot MTA, and gray MTA-Angelus. Oral Surg Oral Med Oral Pathol Oral Radiol Endod 2006;102:809-15.

14. Menezes R, da Silva Neto UX, Carneiro E, Letra A, Bramante CM,Bernadinelli N.MTA repair of a supracrestal perforation: a case report. J Endod 2005;31:212-214.

15. Baek SH, Plenk H Jr., Kim S. Periapical tissue responses and cementum regeneration with amalgam, Super EBA, and MTA as root-end filling materials. J Endod 2005;31:444-449.

16. Bortoluzzi EA, Broon NJ, Bramante CM, Garcia RB, de Moraes IG, Bernardineli N. Sealing ability of MTA and radiopaque Portland cement with or without calciumchloride for rootend filling. J Endod 2006;32:897-900.

17. Torabinejad M, Chivian N. Clinical applications of mineral trioxide aggregate. J Endod 1999;25:197-205.

18. M. Torabeinejad and T.R. Pitt Ford : Antibacterial effects of some root end filling material. The American Association of Endodontists Vo.21, No.8, August 1995.

19. Torabinejad M, Chivian N. Clinical applications of mineral trioxide aggregate. J Endod 1999;25:197-205.

20. M.Torabinejad and T.R.Pitt Ford : Sealing ability of mineral trioxide aggregate when used as a root end filling materials. The American Association of Endodontists Vo.19., No. 12, Dec. 1999.

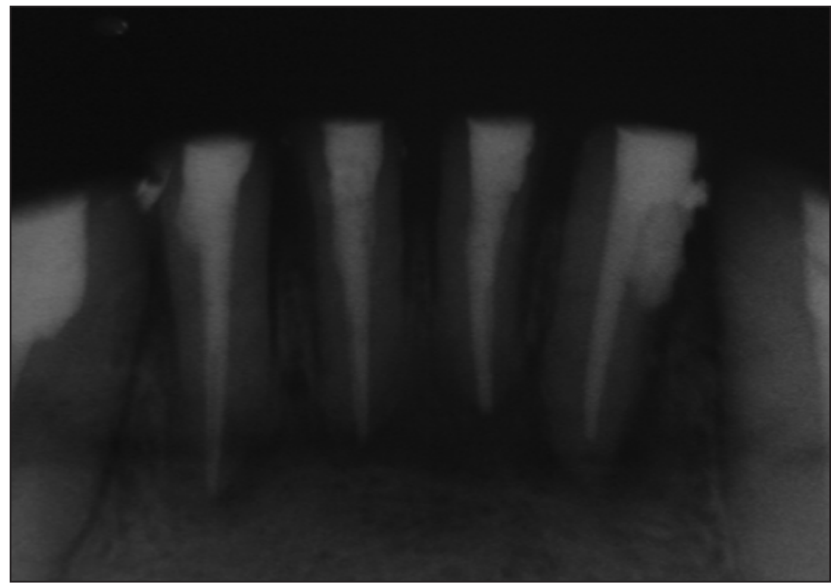

Figure 2: Post-Op MTA Seal

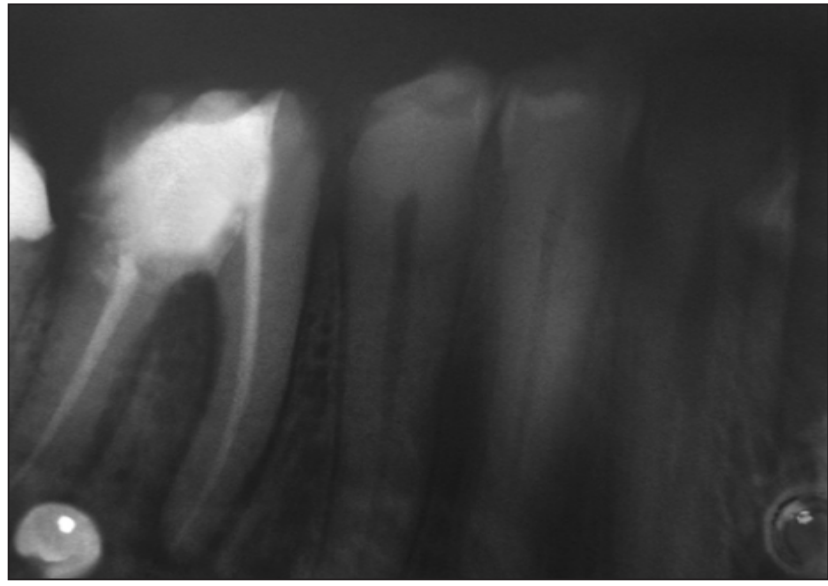

Figure 4 : Post-Op MTA Seal 


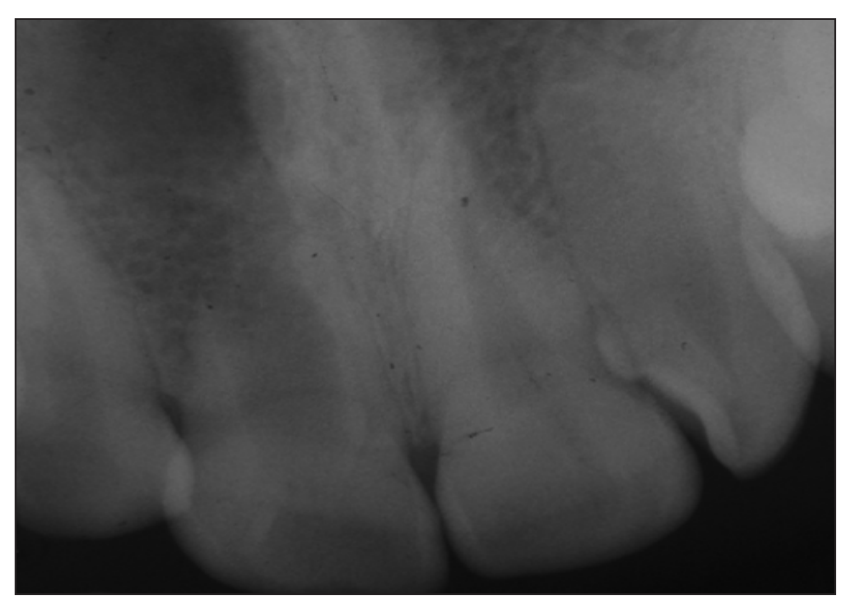

Figure 5: Pre-Op open apex

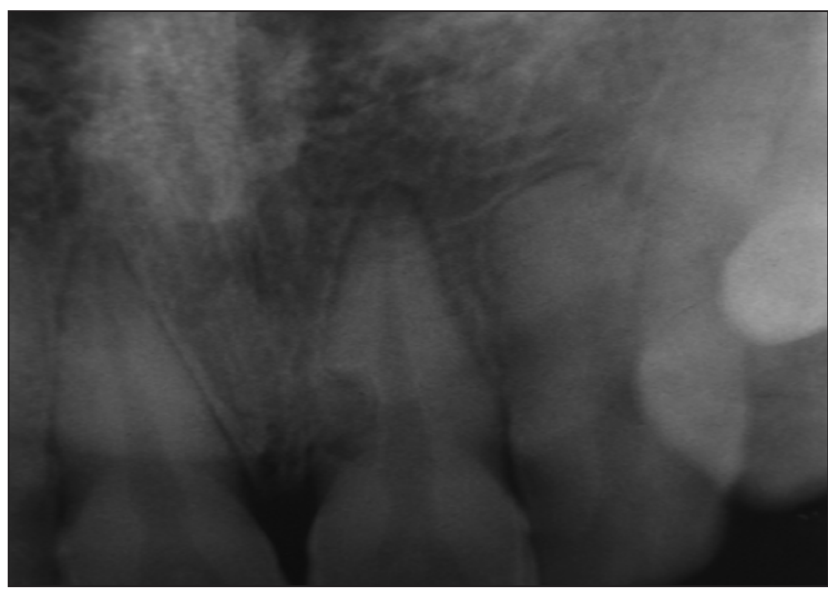

Figure 7: Pre-Op External resorption

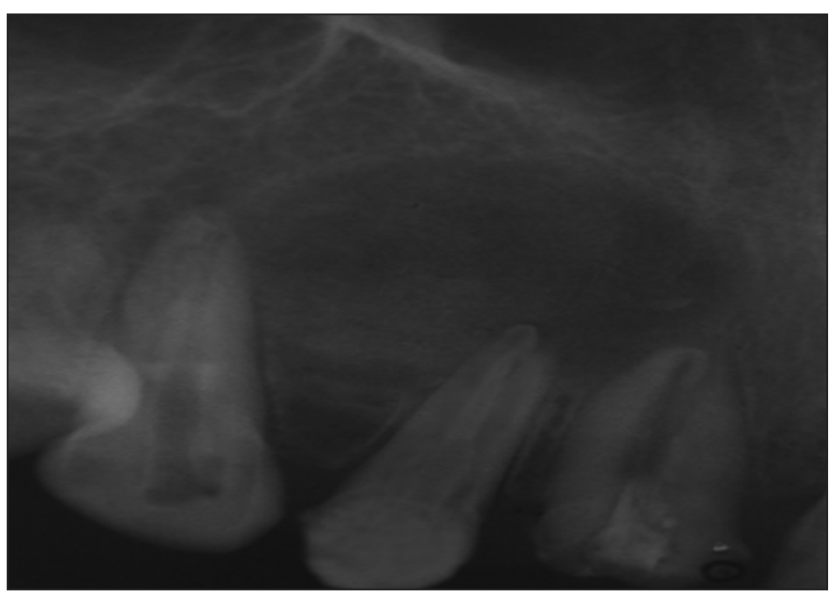

Figure 9: Pre-OP periapical lesion

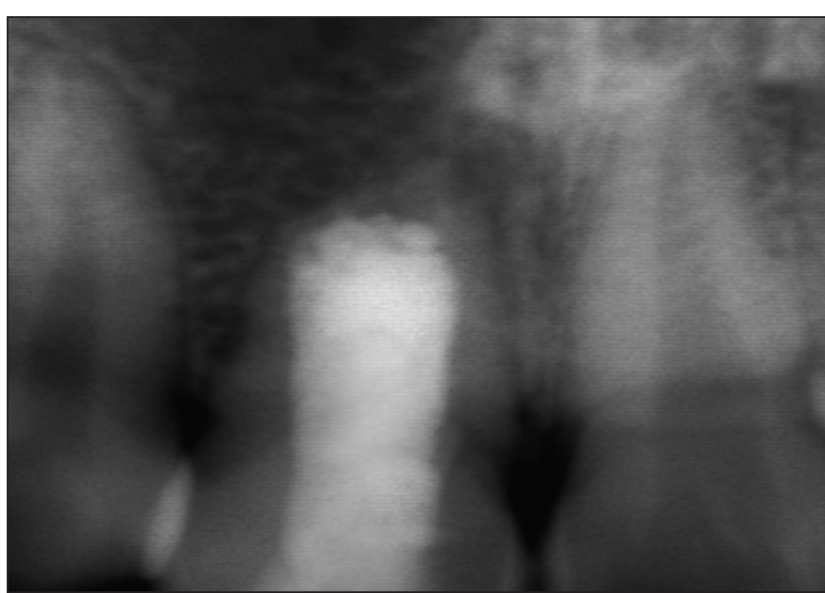

Figure 6: Post-Op MTA Seal

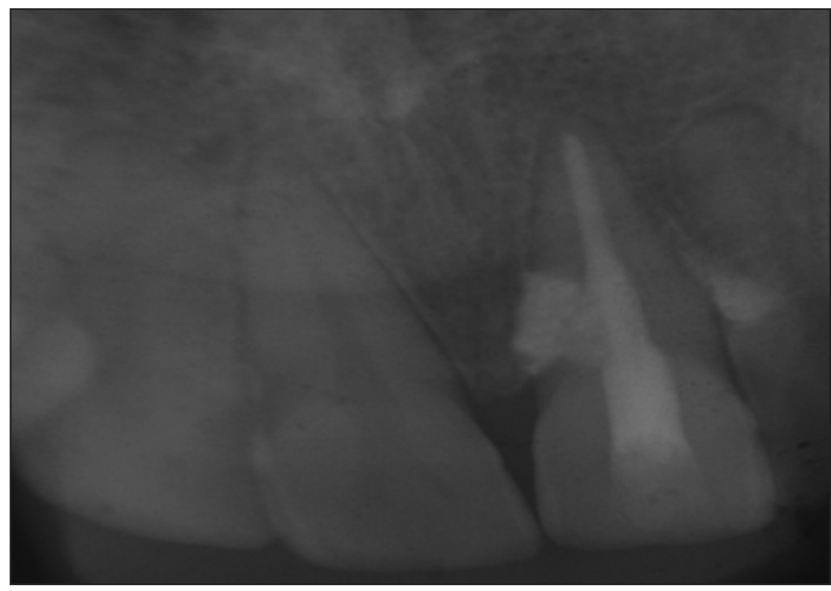

Figure 8: Post-Op MTA Seal

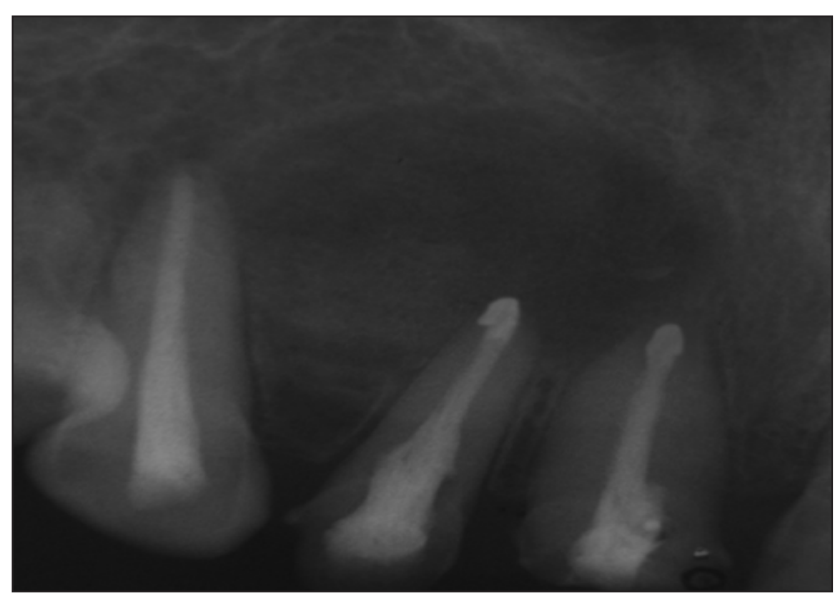

Figure 10: Post-Op MTA retro Seal

IJDA, 3(3), July-September, 2011 